\title{
8
}
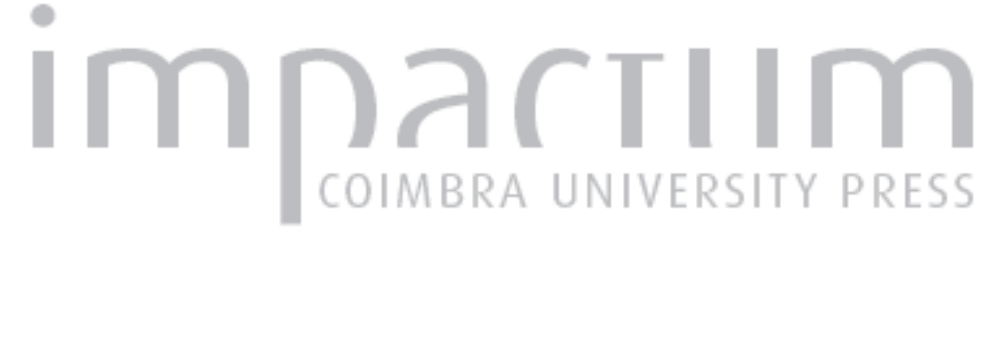

\section{O culto de Santa Comba e o (re)povoamento do Vale do Dão (sécs. X-XI)}
Autor(es):
Veloso, Maria Teresa Nobre
Publicado por: Instituto de História Económica e Social, Faculdade de Letras da Universidade de Coimbra

URL

persistente:

URI:http://hdl.handle.net/10316.2/11974

DOI:

DOI:http://dx.doi.org/10.14195/0870-4147_40_11

Accessed : $\quad$ 26-Apr-2023 12:30:23

A navegação consulta e descarregamento dos títulos inseridos nas Bibliotecas Digitais UC Digitalis, UC Pombalina e UC Impactum, pressupõem a aceitação plena e sem reservas dos Termos e Condições de Uso destas Bibliotecas Digitais, disponíveis em https://digitalis.uc.pt/pt-pt/termos.

Conforme exposto nos referidos Termos e Condições de Uso, o descarregamento de títulos de acesso restrito requer uma licença válida de autorização devendo o utilizador aceder ao(s) documento(s) a partir de um endereço de IP da instituição detentora da supramencionada licença.

Ao utilizador é apenas permitido o descarregamento para uso pessoal, pelo que o emprego do(s) título(s) descarregado(s) para outro fim, designadamente comercial, carece de autorização do respetivo autor ou editor da obra.

Na medida em que todas as obras da UC Digitalis se encontram protegidas pelo Código do Direito de Autor e Direitos Conexos e demais legislação aplicável, toda a cópia, parcial ou total, deste documento, nos casos em que é legalmente admitida, deverá conter ou fazer-se acompanhar por este aviso. 

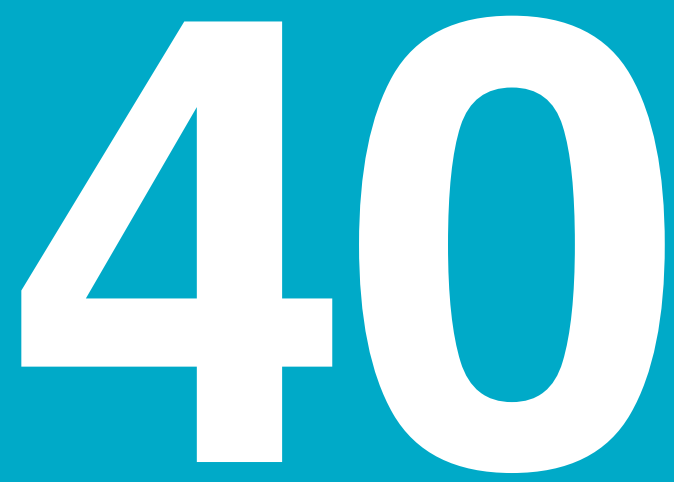

\section{Revista Portuguesa de História}

Faculdade de Letras da Universidade de Coimbra Instituto de História Económica e Social

Coimbra 08/09 
Revista Portuguesa de História

t. XL (2008/2009)

pp. 251-271

\title{
O culto de Santa Comba e o (re)povoamento do vale do Dão (sécs. X-XI)
}

\author{
Maria Teresa Nobre Veloso \\ Faculdade de Letras da Universidade de Coimbra \\ "In ipso est Christianis festum Columbe \\ interfecte in civitate Rubucus in alio Senonia, \\ et est martyr (...)"1
}

No virar do segundo milénio - a 1 de Novembro de 1999 - Santa Comba Dão, sede do concelho do mesmo nome, torna-se cidade. A sua história, porém, remonta muitos séculos atrás. Não nos referimos aos humildes espaços habitados no período romano (ou até anterior) os quais os arqueólogos vão paulatinamente revelando ${ }^{2}$. A ancianidade da referida urbe patenteia-se no seu próprio nome

1 Rubrica de 31 de Dezembro do Calendário de Córdova do ano 961 in FEROTIN, Marius, Osb - Le Liber Ordinum en usage dans l'Église wisigotique et mozarabe d'Éspagne du cinquième au onzième siècle. Roma, 1996 (reed.), p. 449-496.

2 As igrejas matrizes do Vimieiro e de S. João de Areias são dois casos conhecidos de associação entre vetustas sepulturas rupestres da antiguidade e espaços religiosos do período cristão. Cfr. LOURENÇO, Sandra Clara Alves - O povoamento alto medieval entre os rios Dão e Alva. Dissertação de mestrado em Arqueologia (policopiada). Coimbra : Faculdade de Letras, 2005, p. 49-50. 
- Santa Comba - e na série de diplomas (alguns deles originais) do século X que chegaram até nós.

Quem é Santa Comba? Porque foi o seu culto tão difundido, há mais de mil anos em particular na região de Coimbra?

A santa epónima da urbe do Dão é muito, muito antiga. Morreu martirizada em França, em Meaux, no meado do século III durante o governo do imperador Aureliano. A história da mártir repete, mutatis mutandis a de muitas outras que verteram o sangue para dar testemunho de Cristo.

Comba, cujo nome se identifica simbolicamente com inocência ${ }^{3}$, foi coagida a renegar a sua fé. Ante a corajosa firmeza de convicções que demonstrou ao longo dos interrogatórios judiciais, o imperador tentou demovê-la, aliciando-a. Com esse fim, oferece-lhe como noivo o próprio filho. Porém, a jovem recusa veementemente a proposta. O castigo para tal ousadia é terrível: a virgem é encarcerada na cella meretricia. A partir deste momento a sua Passio relata uma série de acontecimentos miraculosos: o algoz fica impedido de cumprir a sentença devido ao inesperado aparecimento de um animal selvagem - uma ursa - no cárcere de Comba; a prisão em que a jovem se encontrava é incendiada

3 Comba procede do nome latino columba, isto é, pomba. De entre as aves referidas na Bíblia, quer no Antigo quer no Novo Testamento, aquela é a que mais se diferencia das restantes pela frequência com que é mencionada. Seria ocioso citar aqui todos os passos bíblicos em que a referida ave é protagonista. Dois deles, no entanto, marcaram desde muito cedo o imaginário cristão: o do dilúvio - Gen. 8,8-12 (especialmente 11: "At illa [columba] venit ad eum ad vesperam portans ramum olivae virentibus foliis in ore suo") e o do baptismo de Cristo - Luc. 3,21-22 (especialmente 22: "et descendit spiritus sanctus corporali specie sicut columba in ipsum"). A pomba é símbolo de paz divina porque (como escreve Tertuliano no seu De baptismo, Cap. - VIII) é "animal simplicitas et inocentiae quod etiam corporaliter ipso felle careat". A pomba era igualmente a única ave que podia ser oferecida em sacrifício. Do exposto pode entender-se melhor os motivos pelos quais vários relatos da morte dos santos mártires representam a alma a sair dos seus corpos sob a forma de pomba. Um dos exemplos mais poéticos é o da virgem Eulália de Mérida - a santa (matamouros) da primeira fase da Reconquista - imortalizada por Aurélio Prudêncio Clemente no hino III do Peristephanon (séc. V). Sobre estes temas cfr. "Colomb" in Dictionnaire d'Archéologie Chrétienne et de Liturgie. Dir. D. Fernand Cabrol e D. Henri Leclercq, III (deuxième partie). Paris : Letouzey et Ané, 1914, col. 2198-2231, especialmente 2203-2213; "Colomb" in Dictionnaire de la Bible publié par F. Vigouroux, vol. II (première partie). Paris : Letouzey et Ané, 1912, col. 846-851; "Pomba" in CHEVALIER, J. e GHEERBRANT, A. Dicionário dos Símbolos. Lisboa: Teorema, 1994, p. 533; "Paloma" in COCAGNAC, Maurice de -Los símbolos biblicos. Léxico Teológico. Bilbao: Desclée De Brouwer, 1994, p. 194-195. Sobre Santa Eulália de Mérida cfr. MARTÍN DE RODRIGO, António Mateus - Santa Eulália de Mérida. La grandeza de lo pequeño. Mérida: Artes Gráficas, 2004, p. 50. 
por ordem de Aureliano, mas o fogo é extinto por súbita e providencial queda de chuva. Então, o imperador furioso manda degolá-la. ${ }^{4}$

O culto a Santa Comba está documentado, de forma segura, desde 595 data em que temos conhecimento da existência do seu túmulo em Sens ${ }^{5}$. A partir do século VI, a devoção à mártir, cuja festa se celebra a 31 de Dezembro, espalhou-se em França como o patenteiam as três dezenas de topónimos, ainda hoje existentes, sob a sua invocação. Em seguida estendeu-se à Hispânia onde actualmente se documentam, desde o Atlântico ao Mediterrâneo, mais de quarenta hagiónimos combenses todos localizados na margem direita do Douro e do Ebro, logo na faixa Norte da Península ${ }^{6}$.

A introdução do culto de Santa Comba na Hispânia cristã resultou da série de intercâmbios político-religiosos que a monarquia das Astúrias estabeleceu com Carlos Magno, em particular, depois do êxito alcançado por Afonso II na aceifa que em 798 o levaria triunfalmente até Lisboa. ${ }^{7}$ Cerca desta data, o rei enviou pelo menos três embaixadas a Carlos Magno $(795,797,798)$. Eginhardo, referindo-se ao Asturiano, informa que o rei se intitulava homo, isto é, vassalo do futuro imperador. $\mathrm{Na}$ realidade, o rei Casto buscava entre os francos o auxílio militar imprescindível para o avanço da Reconquista. Naquele último ano - 798 - as tropas de Carlos Magno avançaram desde Gerona até ao Alto Segre e, em 800, levaram a cabo uma grande razia até Lérida e Huesca iniciando certamente o assédio a Barcelona.

A par dos contactos militares, a Hispânia cristã ligava-se também estreitamente, sob o aspecto religioso, com o reino dos francos. De entre as diversas embaixadas bilaterais, notabiliza-se aquela enviada pelo famoso Beato de Liébana (799) encarregada de se encontrar com Alcuíno em S. Martinho de

4 Os pormenores da Passio combense podem encontrar-se sintetizados em LECLERCQ, H. - "Sens" in Dictionnaire d'Archéologie Chrétienne et de Liturgie, XV (première partie). Paris: Letouzey et Ané, 1950, col. 1206-1207.

5 O rei S. Luís casou-se em Sens a 27 de Maio de 1234. Fez escala, durante três dias, na abadia de Santa Comba localizada perto da cidade. O piedoso rei pediu certamente à jovem mártir que intercedesse a Deus em seu favor num momento tão importante da sua vida. Cfr. LE GOFF, J. - Héros du Moyen Âge, le Saint et le Roi. Paris: Gallimard, 2004, p. 284.

6 Cfr. MOUTA, P. e Oliveira - "Considerações sobre Santa Comba" in Mensageiro de

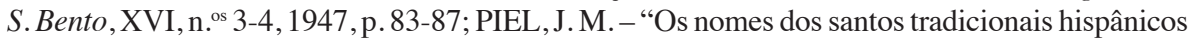
na toponímia peninsular" in Biblos. Coimbra: Faculdade de Letras, vol. XXVI, 1950, p. 283-284; FERRER GRENESCHE, Juan-Miguel - Los santos del nuevo misal hispano-mozárabe. Toledo: Estudio Teológico de San Ildefonso, 1995, p. 145-146.

7 Cfr. SANCHEZ ALBORNOZ, Cláudio - Orígenes de la nación española. El reino de Astúrias. Madrid: Sarpe, 1985, p. 159-161. 
Tours. É deste intercâmbio que resulta, sem dúvida, a divulgação na Gália do século VIII do mito de S. Tiago. Deve-se justamente a Beato, o monge visionário de Liébana, celebrado autor dos comentários ao Apocalipse (786), a propagação da ideia de que aquele Apóstolo evangelizara a Hispânia. Deve-se igualmente ao referido cenobita o famoso hino litúrgico em que S. Tiago é invocado pela primeira vez como patrono e protector da Ibéria.

Das ásperas e recônditas montanhas da Cantábria, eriçadas de cumes gigantescos, ergue-se um emocionado clamor, um lancinante pedido de ajuda celeste para a cristandade que por aqueles tempos corria o risco de soçobrar, para sempre, sob o jugo do infiel: "Oh Apóstol digníssimo y santíssimo, cabeza refulgente y dorada de España, defensor poderoso y patrono nuestro (...) Asiste piadoso a la grey que te ha sido encomendada $(\ldots)^{8}$.

A crescente ligação monástica que se estabeleceu, lato sensu, a partir dos fins do século VIII entre a Hispânia cristã e a Gália, e cujo fim era afastar o Norte da Península da "nefasta" influência da Igreja de Toledo, trouxe o conhecimento e a difusão de novas devoções, entre as quais, a de Santa Comba. Leclercq afirma que já no século VI ou VII se veneravam as relíquias da mártir em S. Miguel de Escalada (León) ${ }^{9}$. Porém, a popularidade da devoção combense fez-se através das casas monásticas beneditinas. Entre elas avultam Trício (Logroño) na Rioja e Bande (Orense) na Galiza. A primeira possuía as relíquias da mártir e, por isso, se intitulava cenóbio Senoniense ${ }^{10}$.

O fascínio pela história de Santa Comba compreende-se no ambiente que se vivia na Hispânia, em particular depois do século VIII. Naquela época, a intolerância religiosa voltava a repetir-se tendo como verdugos os muçulmanos. $\mathrm{Na}$ violência dos combates entre cristãos e islamitas pela disputa da terra, o exemplo da mártir gaulesa servia de suporte à prossecução da luta. Por isso, multiplica-se o número daqueles que a desejavam imitar ${ }^{11}$. Em vários lugares surgem outras Combas cujas histórias de heroísmo reproduzem, com variantes

8 Cfr. Idem, Ibidem, p. 145.

9 Cfr. Dictionnaire d'Archéologie Chrétienne et de Liturgie, XV (première partie). Paris: Letouzey et Ané, 1950.

${ }^{10}$ Santa Comba é actualmente epónima em localidades das seguintes províncias de Espanha: Oviedo, Alava, Burgos, Logroño, Lérida, Barcelona, Gerona, Tarragona, Samora e León. Cfr. PIEL, J. M. - "Os nomes dos santos tradicionais hispânicos na toponímia peninsular" in Biblos, XXVI, p. 284.

${ }^{11}$ Veja-se o exemplo de martírio dado por mulheres durante o domínio agareno da Hispânia apresentado por CARRASQUER PEDRÓS, Maria Sira - Madres Mozárabes. Antropologia cultural, Historia, Espiritualidade. Burgos: Monte Carmelo, 2003 especialmente p. 86; 126-129; 144; 152; 164 e 263. De entre os relatos publicados pela Autora, salienta-se o de Santa Comba de Tábanos (Córdova) martirizada durante o governo de Muhammad I, p. 145-148. 
locais, a de Sens: Santa Comba da Serra (Mirandela), Santa Comba de Basto, Santa Comba de Évora... Santa Comba era igualmente a titular secundária do mosteiro de Rocas (c. Sever do Vouga $)^{12}$.

A lenda da mártir de Coimbra (Celas), festejada a 20 de Julho e relatada poeticamente por António de Vasconcelos, é talvez a mais consistente visto que é a única de cujo corpo existem relíquias guardadas, desde o século XIII, no mosteiro conimbricense de Santa Cruz ${ }^{13}$.

Da popularidade da devoção combense nasceu o desejo de dar às crianças o nome da heroína cuja história tantas vezes era ouvida na Igreja. Porém, é uma vez mais na região de Coimbra que encontramos testemunhos assinaláveis desta realidade: entre 1094-1184 surgem nos documentos do Livro Preto dez mulheres com este nome. Entre elas há proprietárias, doadoras, donatárias, foreiras... Comba era o nome da irmã de D. Paterno, primeiro bispo daquela cidade após a sua reconquista definitiva. Nos arredores de Coimbra encontramos também a freguesia de Casal Comba (c. Mealhada) ${ }^{14}$. Noutras zonas do país o referido nome parece não ter sido tão popular. No entanto, nos Censuais de Braga, Guimarães e Montelongo e Panóias, Santa Comba surge mencionada como orago de duas freguesias já antes da invasão muçulmana ${ }^{15}$. No Liber Fidei está

${ }^{12}$ Livro Preto: Cartulário da Sé de Coimbra. Texto integral. Direcção científica P. ${ }^{\mathrm{e}}$ Avelino de Jesus da Costa. Direcção editorial Manuel Augusto Rodrigues. Coimbra: Arquivo da Universidade de Coimbra, 1999, doc. 126. Citaremos sempre esta obra com as siglas L. P.

${ }^{13}$ Cfr. VASCONCELOS, António de - "A ermida de Santa Comba" in António de Vasconcelos perpetuado nas páginas do Correio de Coimbra: 1922-1941. Coimbra: Arquivo da Universidade de Coimbra, 2000, p. 84-86. Fora de Portugal e de Espanha há também outras Combas: Inglaterra, celebrada a 16 de Março, ou Itália (Rieti) celebrada a 2 de Fevereiro. A primeira, que deu nome à cidadezinha de Cornwall, deve ser identificada com Santa Comba de Sens cujo culto chegou à Inglaterra. Cfr. Dictionnaire d'Histoire et Geographie ecclésiastiques, XIII. Paris: Letouzey et Ané, 1956, col. 321-322.

${ }^{14}$ Cfr. L. P., docs. 5; 27; 40; 229; 280; 317; 320; 434; 581 e 652. Sobre Casal Comba, cfr. L. P., docs. 96, 175, 276. Actualmente, em Portugal, Santa Comba é epónima de vinte e quatro lugares e seis freguesias e orago em cinco destas. Tudo isto se situa a Norte do Mondego com excepção de dois casos: um no concelho de Montemor o Novo; outro no de S. Tiago do Cacém. Cfr. Apêndice, II.

${ }^{15}$ Cfr. COSTA, P. Avelino de Jesus da - O Bispo D. Pedro e a organização da arquidiocese de Braga. 2. ${ }^{\text {a } e d . ~ r e f u n d i d a ~ e ~ a m p l i a d a . ~ B r a g a: ~ E d i c ̧ a ̃ o ~ d a ~ I r m a n d a d e ~ d e ~ S . ~ B e n t o ~ d a ~ P o r t a ~ A b e r t a, ~}$ 1997, vol. I, 470. 
documentada como nome de mulher apenas uma vez em $1135^{16}$. Na região de Arouca encontramos no século XI uma Comba Zadiz e um Casal Comba ${ }^{17}$.

As primeiras referências documentais a Santa Comba Dão acham-se num diploma original com data de 974. Neste documento, o conde Oveco Garcia doa ao mosteiro de Lorvão a Villa de Sancta Columba ${ }^{18}$ da qual estabelece os respectivos limites. Entre eles acham-se nomeadas algumas das freguesias e lugares que actualmente integram aquele concelho: S. Joaninho, Treixedo, Gestosa e S. Jorge.

O século $X$, particularmente a segunda metade, testemunha o arranque do povoamento do vale do Dão. Naquela época, Coimbra reconquistada em 878 e situada na fronteira com os muçulmanos, não oferecia ainda condições suficientemente atractivas para a fixação dos povoadores. Por esse motivo, os reis da Galécia, Ordonho II e seu filho Ramiro II, elegeram para capital a cidade de Viseu. Este facto veio determinar a notável importância do cenóbio lorbanense e influir de modo decisivo no fomento agrário e populacional do vale do rio a que os diplomas medievais chamam Adon ${ }^{19}$.

${ }^{16}$ Liber Fidei Sanctae Bracharensis Ecclesiae. Edição crítica pelo P. Avelino de Jesus da Costa. Braga: Junta Distrital de Braga, 1990, Tomo III, doc. 725. Neste diploma, Comba casada com Alvito Carpinteiro é proprietária nos arredores de Braga.

${ }^{17}$ Cfr. BRITO, Bernardo de - Monarquia Lusitana. Lisboa: Pedro Craesback, 1609, II, p. 351; COELHO, Maria Helena da Cruz - O mosteiro de Arouca do século X ao século XIII. Coimbra: Centro de História da Universidade de Coimbra, 1977, p. 121, 179 e 192.

${ }^{18}$ Santa Columba é ainda hoje o orago da freguesia de Couto do Mosteiro que dista apenas $3 \mathrm{~km}$ da sede do concelho. A festa desta mártir, que tinha lugar no Calendário Moçárabe de 961 a 31 de Dezembro, celebra-se actualmente naquela freguesia, mantendo a tradição ancestral, no último domingo do referido mês.

${ }^{19}$ Cfr. L. P., doc. 2. Os diplomas deste cartulário citam igualmente este rio sob os nomes de Alon, Aom, Aon e Huone. L. P., docs. 1-A, 2-A, 64, 80, 151, 271, 301, 630. O rio Dão nasce na serra do Pisco (c. Aguiar da Beira) e percorre $89,5 \mathrm{~km}$ antes de lançar as suas águas no Mondego. Aquele edílico rio desaguava, outrora, no desaparecido lugar de Foz do Dão submerso pela barragem da Aguieira em 1977. Vid. FERREIRA, Francisco António Antunes Gonçalves - Santa Comba Dão. Uma monografia. Santa Comba Dão: Câmara Municipal de Santa Comba Dão, 2005, p. 73. O principal tributário das águas deste rio é o Cris que banha a parte Norte do concelho. Este bucólico curso de água é formado pelos regatos que descendo do Caramulo se juntam no vale de Besteiros. No século XVIII, António Carvalho da Costa cita, um por um, o nome dos ribeirinhos: "Esporão nasce na Póvoa da Margem; rio Castelãos que nasce no lugar de Cadraço; ribeyro de Xudruro que nasce na Fonte Freja; ribeira de Guardão que nasce na fonte das Amexieyras; rio Santiago que nasce na Muzarela. Todos estes rios e ribeyros ajuntando-se no valle de Besteyros, formão o rio Crins que perde o nome, metendo-se no Mondego junto com o rio Dam, por bayxo da Villa de Santa Comba Dão". Cfr. COSTA, António Carvalho da Corografia Portuguesa e descripçam topográfica do famoso reyno de Portugal com as notícias 
A escolha de Viseu para capital do reino não era aleatória. Além da segurança que oferecia (e a que já fizemos referência), era a principal cidade a sul do Douro situada in finibus Galecie ${ }^{20}$. Além disso, uma ancestral tradição localizava em Viseu a sepultura do último rei dos visigodos - Rodrigo - que depois de morto na batalha de Guadalete (19 de Julho de 711) para ali teria sido transportado pelos seus fiéis facto que dava à cidade um inegável prestígio. Dois séculos depois da perda da Hispânia, em plena Reconquista, Ordonho, secundogénito de Afonso Magno, recebeu em herança o reino da Galécia. Por aquela época esta vasta região compreendia, não só a actual Galiza, mas também outro amplo território, mais a Sul, que se estendia até ao Mondego. Ordonho II fixou-se em Viseu e para aqui carreou o produto do imenso saque resultante da campanha vitoriosa que efectuou contra os muçulmanos em $911^{21}$.

Deve-se decerto à estada do rei em Viseu o seu casamento com a filha do nobilíssimo presor de Coimbra Hermenegildo Guterres ${ }^{22}$. A morte do rei de Leão

das fundações das cidades, villas et lugares [...]. 2. ${ }^{\text {a }}$ ed. Lisboa: Valentim da Costa Deslandes, Tomo II, MDCCVIII, p. 193. A grafia correcta daquele afluente do Dão deve ser CRIS atendendo à sua etimologia - Crines, Crins. Cardoso da Costa no século XVIII escrevia, como se lê no passo citado - Crins.

${ }^{20}$ Esta expressão é empregue em 933 para localizar o cenóbio lorbanense: "subtus monte Lauribano in finibus Gallecie". Cfr. PORTUGALIAE Monumenta Historica a seculo octavo post Christum usque ad quintum decem jussu Academiae Scientiarum Olisiponensis edita-Diplomata et Chartae. Olissipone: Typis Academicis, 1867, vol. I, doc. XXXVII, p. 23. Viseu era um lugar relativamente bem servido por vias de comunicação que permitiam chegar a Braga com alguma rapidez. Cfr. RIBEIRO, Orlando - "Em torno das origens de Viseu" in Revista Portuguesa de História. Coimbra, 1971, tomo XIII, p. 216.

${ }^{21}$ Sobre a ancestral tradição que faz de Viseu o lugar de sepultura de el-Rei Rodrigo cfr. SANCHEZ ALBORNOZ, Cláudio - Orígenes de la nación española. El reino de Astúrias. Madrid: Sarpe, 1985, p. 86. Em Viseu foi morto Afonso V (1028), vitimado por uma flecha muçulmana, durante o cerco que efectuava à cidade. A data da campanha vitoriosa de Ordonho II deve situar-se em 911 visto seu pai, Afonso III, o Magno, ser ainda vivo: " siquidem dum pater adhuc viverat, et ipse galliciencibus dominaretur, collecto totius provinciae exercitu Beaticam provintiam petiit. Dein vastatis circumquaque agris et villis incencis, cum maximo captivorum spoliorumque numero, ad Visensem reversus est urbem”. Cfr. PERES, Damião in História de Portugal. Barcelos: Portucalense Editora, Vol. I, MCMXXVIII, p. 449-450. Relaciona-se com este período de segurança e prosperidade para os cristãos a construção da emblemática igreja moçárabe de S. Pedro de Lourosa (c. Oliveira do Hospital) erigida em 912 sobre a margem do rio Alva em plena serrania beirã. Hoje, volvidos quase onze séculos sobre o ano em que este templo foi sagrado (a data encontra-se escrita em caracteres unciais na própria igreja - Era $D C C C C L$ ), continua a ser comovedor recolhermo-nos sob os seus característicos arcos em ferradura docemente iluminados pela claridade vespertina filtrada pelo ajimez colocado sobre a porta da fachada poente.

${ }^{22}$ Hermenegildo Guterres, fiel de Afonso Magno, era casado com Ermesenda Gatones neta do rei Ramiro I. 
obrigaria Ordonho, por razões administrativas, a deslocar a sede do governo para esta cidade ${ }^{23}$. Mas as raízes da sua ligação aos magnates do Sul do Douro estavam lançadas. Um dos seus filhos, Ramiro, não só foi criado no território que actualmente é Portugal, como contraiu matrimónio com uma fidalga da mais alta nobreza conimbricense - Adosinda Guterres ${ }^{24}$. Morto Ordonho II, a partilha do reino fez recair em Ramiro o governo da Galécia do Sul25. Uma vez mais Viseu se torna capital régia.

Face ao exposto não custa perceber a atracção dos magnates portucalenses pela região viseense. Um dos exemplos mais expressivos é protagonizado pela condessa Inderquina [Aires] Palla ${ }^{26}$. Em 961, a fidalga concede ao mosteiro de

${ }^{23}$ Garcia, rei leonês, era irmão de Ordonho. As Astúrias tinham cabido em sorte a outro filho de Afonso Magno - Fruela.

${ }^{24}$ As ligações familiares do rei Ramiro II à nobreza condal conimbricense são bem conhecidas depois do esclarecedor estudo feito por Emílio Sáez. Adosinda Guterres, mulher deste rei, era também sua prima coirmã visto que a fidalga era filha de Gutier Osoreis e Ildôncia Mendes. Esta era irmã da rainha Elvira Mendes, mãe de Ramiro. Pela mesma razão, o rei era igualmente sobrinho de Inderquina Mendes Palla. Ramiro II deve ter sido criado na região de Guimarães visto que foi amamentado pela condessa Ónega mulher do conde Diogo Fernandes, ou seja, Ramiro era irmão colaço de Mumadona Dias. Sobre mais pormenores dos laços familiares do citado rei cfr. SÁEZ, Emilio - "Ramiro II, rey de "Portugal" de 926 a 930" in Revista Portuguesa de História. Tomo III. Coimbra, 1947, p. 271-290.

${ }^{25}$ A Galecia do Norte - correspondente grosso modo à actual Galiza - coubera a Sancho Ordonhes. O reino de Leão, zona mais importante e cabeça da monarquia, foi pertença do primogénito de Ordonho II. Cfr. SÁEZ, Emilio - ob. cit., p. 286-288.

${ }^{26}$ D. Inderquina [Aires] Palla era uma rica e distintíssima fidalga. Julga-se que seria filha de Aires Mendes, que regeu o condado de "Eminio" (911-924), e de Ermesenda Gosendes. Por isso, estava estreitamente aparentada (bisneta) com o famoso presor de Coimbra Hermenegildo Guterres. O inusitado nome desta fidalga, que aparece mencionado apenas uma vez no L.P. (doc. 111), leva-nos para sítios "remotos" em busca da sua origem. Provinha, decerto, do lugar que fora berço da avó materna desta ilustre dama que, como ela, se chamava também Inderquina Palla. É possível que este estranho nome, usado por avó e neta, proviesse da região Pirenaica ou talvez das Astúrias. Palla é uma palavra pré-latina que, segundo Joseph M. Piel, pode ser encontrada naquela zona com o significado de "vertente íngreme e lisa". Mas, continua o mesmo Autor, Palla pode também significar abrigo. Talvez seja neste sentido que o dito nome é usado por estas duas senhoras. Dada a enorme importância social que possuíam, quem se acolhesse à sua protecção ficaria a salvo. Em abono da nossa hipótese cfr. um passo do romance castelhano medieval "Os sete infantes de Lara" no qual a protagonista abriga, sob o seu manto, o escudeiro perseguido: "Et el escudero quando los vio venir, dio defuyr para doña Lanbria, et ella tomolo so su manto". Cfr. SANTOS, Maria do Rosário Prata Ferreira dos - A lenda dos sete infantes. Arqueologia de um destino épico medieval. Coimbra: Faculdade de Letras da Universidade de Coimbra, 2005 (dissertação de doutoramento policopiada), p. 704. Pala é actualmente o nome de uma freguesia do concelho de Mortágua que é vizinho do mosteiro do Lorvão. Existem, e são conhecidas, outras nobilíssimas fidalgas portadoras daquele nome (Inderquina) em regiões mais próximas da provável origem do mesmo. Trata-se das parentes da esposa de Rodrigo Dias, 
Lorvão um munificente conjunto de bens, entre eles o mosteiro de S. Salvador de Speraindei. Esta Casa há muito deixou de existir. A sua vasta fortuna reverteu a favor do cenóbio lorbanense. Mas o rasto do velho ascetério de monjas da cidade de Viriato não se perdeu totalmente. A toponímia e o acurado estudo de Joaquim da Silveira fizeram regressar à memória humana o local preciso onde aquele outrora se erguia - Mosteirinho - moderno lugar da freguesia de Santa Ovaia de Couto de Baixo, concelho de Viseu. Um dos conjuntos de bens detidos pelo vetusto ascetério situava-se exactamente numa área composta pelas melhores terras agrícolas do vale do Dão ${ }^{27}$.

As referências documentais a Santa Comba voltam a aparecer em 981. Neste ano, a 22 de Dezembro, a conde de Coimbra Gonçalo Moniz doa ao mosteiro lorbanense uma vasta área situada de ambos os lados do rio Dão e que actualmente corresponde a parte dos concelhos de Santa Comba, Tondela e Carregal do Sal: Treixedo, Vila Nova da Rainha, Gestosa, Nagosela, Silvares, S. João de Areias, Papízios e Currelos ${ }^{28}$. As razões apresentadas pelo magnate

"O Cid". D. Ximena tinha na sua família, além de uma antepassada longínqua, uma sobrinha chamada Enderquina. Na região de Castela (Castrojeris) conhece-se, pela mesma época, outra ilustre dama com o mesmo nome - a mãe de Garcia Ordonhes, conde de Nájera, o valido de Afonso VI - D. Anderkina. Sobre D. Inderquina Mendes Palla e sua neta, D. Inderquina [Aires] Palla, cfr. MATTOSO, J. - A nobreza medieval portuguesa. A família e o Poder. Lisboa: Estampa, 1981, p. 129-130; 132-133. Sobre o nome Palla, cfr. PIEL, J. M. - "Nomes de lugar referentes ao relevo e ao aspecto geral do solo" in Revista Portuguesa de Filologia, vol. I. Coimbra, 1947, p. 187. Sobre as parentes de D. Ximena Dias, cfr. o quadro genealógico apresentado por MARTÍNEZ DÍEZ, Gonzalo in Alfonso VI señor del Cid, conquistador de Toledo. Madrid: Temas de Hoy, 2003, p. 266. Sobre D. Anderkina, mãe do conde Garcia Ordonhes, cfr. SÁNCHEZ-PAGíN, José M. Canal - "El conde García Ordoñez, rival del Cid Campeador. Su familia, sus servicios a Alfonso VI" in Anuario de Estudios Medievales, 27, Barcelona, 1997, p. 754-756.

${ }^{27}$ Estas terras localizam-se em zona facilmente irrigada pelo curso dos rios Dinha, Asnos, e Dão. O povo reconhece esta realidade afirmando: "Entre o Dinha e o Dão há um rio em que todos têm quinhão". O citado diploma de D. Inderquina (961) menciona os topónimos tal como hoje os podemos encontrar: "Ego (...) Inderquina ataque Palla (...) offero (...) villa Speraindeo (...) et adicio etiam mea villa Savugosa per suis locis et terminis antiquis et Laurosa et Ferronio et vineas que sunt in ripa Pavie et villa Sancte Eolalie cum omnibus prestationibus suis (...)". D.C., doc. 84,p. 53. Sobre a identificação dos lugares, cfr. SILVEIRA, Joaquim da - "Toponímia Portuguesa. (esboços)" in Revista Lusitana, vol. 33, 1935, p. 250-251 e CARVALHO, Amadeu Ferraz de - A terra de Besteiros e o actual concelho de Tondela.(Esboço histórico e toponímico). Nova edição preparada e dirigida por António Manuel Pelicano Matoso Martinho. Tondela: Câmara Municipal, 1981. Resta apenas referir que o nome da mártir de Mérida foi deturpado, mas Santa Eulália continua a ser a santa epónima da freguesia de Santa Ovaia de Couto de Baixo.

${ }^{28}$ Gonçalo Moniz era bisneto do presor de Coimbra - Hermenegildo Guterres. Daí os vastos domínios que possuía em terras combenses (e noutras vizinhas) as quais são referidas no citado documento em 981: "Ego (...) Gondizalvus Muniz (...) placuit nobis (...) ut faceremus ad ipsius loci et sanctorum Sancti Mametis et sancti Pelagii textum scripture testamenti (...) 
conimbricense para tão ampla doação encontram-se expressas no citado diploma de 981. Gonçalo Moniz espera com estas benemerências feitas ao mosteiro alcançar, por intercessão dos santos mártires que ali repousam, em particular S. Mamede e S. Paio, o perdão para os seus crimes. E, embora ali não seja especificamente mencionado, sabemos que um deles o deveria atormentar de modo especial - aquele que perpetrara contra Sancho o Gordo, em 965, e que levaria à morte do rei ${ }^{29}$.

Quatro anos mais tarde, o cenóbio lorbanense recebe outra doação milionária - a do conde Mónio Gonçalves. Nesta, o outorgante, filho do benfeitor antecedente, concede ao dito mosteiro (para além de outras coisas) metade da sua villa de Santa Comba ${ }^{30}$.

Este primeiro surto de desenvolvimento combense e do vale do Dão foi bruscamente interrompido. Pelos finais do século X, a ofensiva de Almançor que atingiu também estas terras (o chefe muçulmano fez escala em Viseu em 997 quando se dirigia para Santiago de Compostela), subverteu a ordem e o

de omni nostra hereditate quam habemus de villa nostra propria que vocitant Traxede cum suo monasterio discurrente ribulum Adon (...).Adicimus etiam alias villas ad ipsum monasterium deserviendum ecclesia de Traxedilina ubi est sepultura ejus cum adjucionibus suis cum villa Genestosa et de alia parte villa Negosela (...) et ultra ribulo Adon villa que vocitant Papizinos. Et alia villa Olivaria de Currelos (...) et villa de Silvares (...) et villa de Sancto Johanne de Teliada (...)". Cfr. D.C., doc. 130. Este diploma foi resumido em português por BRITO, Bernardo de - Monarquia Lusitana, II. Lisboa: Pedro Craesbeck, 1609, p. 352.

${ }^{29} \mathrm{O}$ crime teve lugar no mosteiro do Lorvão. Gonçalo Moniz ofereceu a Sancho uma maçã envenenada como vingança pelo facto do rei diminuir os amplos poderes que o magnate conimbricense detivera até àquela data. Cfr. MATTOSO, J. - A nobreza medieval portuguesa, p. 121-122.

${ }^{30}$ Além da villa de Santa Comba da qual dá os respectivos limites, Mónio Gonçalves concede, do mesmo modo, a Lorvão muitos outros bens que patenteiam a sua imensa fortuna: "Offero sancte Eglesie vestre, cujus baselica esse dinoscitur locum que dicitur Lauribano, (...) villa mea propria quos vocitant Sancta Columba cum ajacenciis suis villares cum suas eclesias vobis domno Benjamin abba et congregatjo vestra et ipsa villa cum exitus montium ingressus et regressus cortes cum casas intrinsecus eorum cubus cum cibaria et cubas cum bivere lectus cadedras mensas cum panales mensorios pannos siricos laneos et lineos aurum argentum cavallos mulos et asinos cellas frenos sporas spadas scudos et lanzas equas boves et vacas et obelias seu et porcos ita volatilium vineas et pomares et suautus terras ruptas vel inruptas varcenas ortales molinos vel quantum a prestitum ominis est. Et dividit cum villa Alvarini per montis et arcas et terminos fortes usque in rivulo Crinis cum ipso monasterio Sancti Georgi et de alia parte cum Sancti Jhoanni per illo fontanum perge per montis dividet cum villa Trexedi per locis et terminos anticos usque in rivulo Adon". Cfr. L. P., doc. 1, p. 3. O passo que acabámos de transcrever pertence ao diploma original do século X. Cerca de três centúrias mais tarde a Sé de Coimbra, então proprietária das terras em apreço, transcreveu o citado diploma para o Livro Preto. Ambos os documentos estão publicados integralmente no cartulário coimbrão dado à estampa em 1999. 
progresso que lentamente se alcançara fomentado pelos senhores e intensificado pelas casas monásticas. Basta relermos o passo de um documento datado de 13 de Dezembro de 1005 para percebermos a assustadora devastação causada ante o avanço dos agarenos: "Dubium quidem non est sed multum manet nobis cognitum, in veritate, de eo quod venerunt gentes hismaelitarum in sede Colimbriense; pervenerunt ad devastandum patriam, usque adeo urbis Durio; devastarunt civitates et portelas per gladio imperio sub regimine ipsas gentes; devastarunt omnes locos sanctos ejus et in diebus ipsius permanente ${ }^{31}$.

Ante a fuga dos senhores, coube às instituições monásticas a ingente tarefa de recuperar as terras devastadas. No caso presente é Lorvão que protagoniza esse esforço.

A reconquista dos territórios arrasados pelos muçulmanos no fim do século $\mathrm{X}$ foi lenta e eivada de dificuldades. Só na segunda metade do século XI Fernando Magno submete definitivamente às forças cristãs as cidades de Seia (1055), Lamego (1057) e Viseu (1058). Coimbra permanecerá por mais seis anos sob o jugo agareno.

A reconquista da cidade do Mondego está profundamente ligada à inestimável colaboração que o monarca recebeu de Sesnando David. Este moçárabe, natural

${ }^{31}$ L. P., doc. 136, p. 207. Vid. igualmente doc. 115, p. 176: "Et supervaluerunt gentes hismaelitarum super christianos et ipse abbas in amore de fide Christi fugivit ante ipsas gentes (...)". Sobre as investidas de Almançor, cfr. AZEVEDO, Rui de - “A expedição de Almançor a Santiago de Compostela em 997, e a de piratas normandos à Galiza em 1015-1016. (Dois testemunhos inéditos das depredações a que então esteve sujeito o Território Portucalense entre Douro e Ave)" in Revista Portuguesa de História, t. XIV, 1974, p. 73-93. No decurso da referida expedição, Coimbra foi novamente perdida. A ofensiva muçulmana só abrandou depois da morte do temido guerreiro agareno. Almançor faleceu a 10 de Agosto de 1002 depois de derrotado (segundo conta a lenda) na fortaleza roqueira de Calatanãzor ou, "como se diz em arábico, Alcantanaçor", isto é, penedo do abutre. Alguns afirmam que morreu de desgosto num lugar chamado Bordecorreja "quatro legoas acima de Osma" (perto de Berlanga, Espanha). Foi sepultado em Medinaceli. Cfr. BRITO, Bernardo de - Monarquia Lusitana, II. Lisboa: Pedro Craesbeck, 1609, p. 362. Bernardo de Brito transcreve, no início do século XVII, o relato lendário sobre os últimos dias do chefe agareno. O referido Autor parece seguir a versão dos acontecimentos apresentada tardiamente por D. Rodrigo Ximenez de Rada ou, com maior probabilidade, por Afonso X na Primera Crónica General. Porém, lendo os relatos muçulmanos coevos do hayib de Córdova, conclui-se que o mesmo pereceu vítima da terrível doença que o atormentava há longos anos - uma artrite gotosa. A viagem de S. Millán de la Cogolla (Rioja), lugar da última campanha de Almançor, até Medinaceli, onde veio a falecer, foi um verdadeiro martírio se tivermos em conta a distância que separa aqueles lugares $-260 \mathrm{~km}$, as altas temperaturas que se fazem sentir naquela região em Julho e Agosto e, em especial, o debilitadíssimo estado de saúde de Almançor que deve ter sido transportado durante catorze dias "en litera a ombros". Cfr. MARTÍNEZ DÍEZ, Gonzalo - el condado de Castilla (711-1038). La Historia frente a la leyenda. II. Valladolid: Junta de Castilla y León - Marcial Pons Historia, 2005, p. 566, 575 e 580-584. 
da região de Coimbra mas vivendo em Sevilha ao serviço dos ismaelitas, foi o guia seguro, o diplomata experiente e o militar fiel de Fernando Magno na árdua tarefa de recuperar para a Cruz a medina Coimbra ${ }^{32}$.

No entanto, o protagonismo da ajuda oferecida àquele rei, é reclamada pelo mosteiro de Lorvão. Em documento transcrito no século XVI por Pedro Álvares Nogueira, o referido cenóbio desempenha um papel decisivo na tomada da cidade ${ }^{33}$. Conhecedores como ninguém da topografia da citada urbe, observadores atentos dos hábitos dos sarracenos que chegavam a aproximar-se de Lorvão para caçar veados, os monges arquitectam um audacioso plano para convencer Fernando Magno a tomar, pela força, a cidade. Iludindo os mouros, dizendo-lhes que se deslocavam a Silos orationis causa, dois monges dirigem-se a Carrión, onde naquele tempo se encontrava o rei, convencendo-o a investir sobre Coimbra com o fim de a reconquistar. O longo e duro assédio feito à cidade lançou o desânimo nas hostes cristãs a quem faltavam já os mantimentos. Mas o mosteiro estava vigilante e socorreu com víveres os cristãos famintos. Recuperada a cidade, o rei agradecido decide oferecer àquele cenóbio parte do saque resultante da conquista. Porém, os monges demonstrando uma admirável abnegação e um louvável desprezo pelos bens materiais, recusam a munificente oferta régia. Suplicam apenas ao monarca que lhes confirme as possessões com que os seus antecessores os haviam distinguido ${ }^{34}$.

Este relato pode ser apócrifo destinando-se a legalizar, sem contestação, a posse da vasta fortuna lorbanense. Todavia, aquele reflecte parcialmente uma realidade inquestionável - o valiosíssimo contributo do cenóbio no esforço repovoador do vale do Dão ${ }^{35}$.

${ }^{32}$ O rei recompensa D. Sesnando confiando-lhe o governo do território a Sul do Douro cujo centro passou a ser Coimbra. Sobre Sesnando David e a sua acção na reconquista de Coimbra, cfr. VELOSO, Maria Teresa Nobre - "a região de Cantanhede segundo os documentos do Livro Preto da Sé de Coimbra" in Revista Portuguesa de História, t. XXXV, 2001-2002, p. 179-184.

${ }^{33}$ Cfr. Livro das Vidas dos Bispos da Sé de Coimbra de Pedro Álvares Nogueira. Nova edição. Transcrição de Maria Teresa Nobre Veloso. Introdução de Manuel Augusto Rodrigues. Coimbra: Arquivo da Universidade de Coimbra, 2003, p. 11-14. Este relato foi também publicado por Bernardo de Brito in Monarquia Lusitana, II, p. 377-379v. juntamente com a respectiva tradução portuguesa, p. 379v.-380.

${ }^{34}$ Os monges, além de recusarem a oferta régia, apresentaram-se perante Fernando Magno oferecendo emblemáticas jóias para ajudar na tarefa de reconstrução do território: "ipsi fratres ad me regem Fernandum (...) aduxerunt mihi istam scripturam cum corona argenti et auri quae fuerat de rege Vermudo et dederat eam Gondisalus Monis in monasterio ad honorem Dei et Sancti Mametis. Vidi ego coronam quomodo erat ornata cum lapidibus praeciosis (...)". Cfr. Livro das Vidas dos Bispos da Sé de Coimbra, p. 13.

${ }^{35}$ AZEVEDO, Rui de - “O mosteiro de Lorvão na Reconquista cristã." Separata do Arquivo Histórico de Portugal, I. Lisboa, 1932. 
Volvidos menos de quarenta anos sobre a reconquista de Coimbra, em Outubro de 1102, Eusébio, prior do referido mosteiro, outorga carta de povoamento aos habitantes de Santa Comba e Treixedo concedendo-lhes determinados direitos e prerrogativas principalmente àqueles que - como pode ler-se no referido diploma - "venerunt vel venerint ad habitandum adque hedificandum in eis sine ulla temporis immutatione". Reconhece igualmente que tenham este direito, não só eles, mas também os seus descendentes tempore infinito. O citado documento permite-nos ainda conhecer os principais rendimentos dos povoadores das referidas villae: cereais, legumes, vinho, linho e caça, não só coelhos, mas também veados. Ficavam os referidos povoadores com ampla liberdade de movimentos. E se quisessem buscar outras paragens podiam fazê-lo sem, no entanto, ter autorização para doar ou de qualquer outra forma alienar os bens que o mosteiro lhes confiara ${ }^{36}$.

Mas a supremacia incontestada e exclusiva de Lorvão sobre o ubérrimo território de Santa Comba em breve ia desaparecer. Face às novas condições de segurança, outros senhores passam a interessar-se por aquela região. Foi o que sucedeu com o alcaide de Besteiros (Tondela) que disputou acesamente àquele cenóbio a posse ao direito de povoamento das citadas terras. $\mathrm{O}$ relato do litígio havido entre as duas partes é feito pelo abade lorbanense num diploma de Maio de 1103 onde está exarada a sentença relativa ao dito litígio. Mido, alcaide de Besteiros, ousara disputar a Lorvão direitos ancestrais e portanto indiscutíveis: "Ego Eusebius prior Laurbonensis cenobii reedificare adque populando, restaurare, consensu rectorum patrie sive dominorum Hanrricii comitis adque Monionis consulis castrum vocabulo Sancta Columba territorio Visense". Porém, apesar da posse

36 "Elegimus itaque, sive uterque inter vos convenimus hoc mos electum, ut quisquis ad plantationem earum villarum venerunt, vel venerint ad habitandum adque hedificandum in eis sine ulla temporis immutatione habeant hoc forum ipsi et posteritates eorum post eos tempore infinito. Id est in obsequium ipsius laurbanensis monasterii cui testate esse sine dubio noscuntur et a eo quo consilium adque fortitudo in turrium edificationes et populatorum adquisitiones adque omnibus alimentis quibus herema solent populare processit ad unoquoque bove duos quarteiros de cibarie quorum sit tercia tritici et tercia centeni et tercia milii; de leguminibus autem quisquis seminaverint tribuat unum almutem; de montariis vero elegimus uniuscujusque venati lumbum tribuere, de conelariis quoque inter quindecim dies unusquisque unum conelium, de lino et vino VIII. ${ }^{a}$ (...). Hoc tributum pedestribus imposuimus sive terre cultoribus ab omni censu liberos adque excusatos esse statuimus omnes cavallarios pene semper ingenuos. Et hoc inter nos sit notum ut siquis populatorum voluntarie abire in alium locum licet nostrum vele cujuslibet voluerit non habeat licentiam vendendi vel donandi neque testandi in partem aliquam extraneam nisi tantum solummodo monasterio vel monasterii supradicti Laurbani tributariis". Cfr. L.P., doc. 68, p. 114-115. 
do referido lugar estar documentada - continua o abade - por escritura outorgada por Oveco Garcia e Mónio Gonçalves, o referido alcaide, valendo-se da autoridade em que estava investido - virtute sue potestatis - colocou homens seus a trabalhar naquele lugar. $\mathrm{O}$ mosteiro reagiu e, uma vez que D. Henrique estava ausente em Jerusalém, apresentou-se perante a infanta D. Teresa e Soeiro Mendes que aconselharam os litigantes a aguardar o regresso do Conde. No entanto, apesar do acordo estabelecido, o alcaide de Besteiros dirige-se a Castela onde, perante Afonso VI, apresenta as suas razões. O imperador reconhece então ao referido alcaide e a seu sobrinho o direito a metade do usufruto vitalício daquele lugar. Posto isto, os bens em litígio devem regressar à posse do mosteiro ${ }^{37}$.

A sentença de Afonso VI relativa aos direitos de povoamento de Lorvão em Santa Comba era apenas o início de um processo que levaria o mosteiro à perda da situação de privilégio que usufruía há pelo menos dois séculos. Assim, em Julho de 1109, D. Henrique e sua mulher, dando cumprimento às ordens vindas de Roma, concedem à Sé de Coimbra o referido cenóbio justificando tal outorga com a carência de bens materiais que por aqueles dias vivia a Igreja Mãe desta cidade ${ }^{38}$.

Mas a importância de Lorvão não se extinguiu. Logo a 19 de Março de 1116 D. Gonçalo, bispo da referida urbe, considerando a necessidade de restaurar aquele antiquíssimo cenóbio (que lhe tinha sido doado sete anos antes pelos ditos Condes) nomeia como abade dele o prior Eusébio e entrega-lhe os respectivos bens determinando igualmente que a eleição dos futuros abades se fizesse com o beneplácito da sé à qual o referido mosteiro ficava sujeito $^{39}$.

O século X marca, sem dúvida, o arranque do povoamento das terras de Santa Comba. As villae doadas neste século pelos condes de Coimbra ao mosteiro de Lorvão apresentam limites grosso modo coincidentes com aqueles que actualmente integram a área total daquele concelho $-115 \mathrm{~km}^{2}$.

Após as campanhas vitoriosas de Fernando Magno e, em especial, depois da conquista definitiva de Coimbra em 1064, o povoamento de Santa Comba beneficiou de uma grande expansão uma vez que no século XII se encontram

${ }^{37}$ Cfr. L.P., doc. 80, p. 127-128.

${ }^{38}$ Cfr. L.P., doc. 59. D. Henrique obedecia às recomendações da Reforma Gregoriana que, entre outras coisas, visava eliminar os chamados mosteiros próprios.

${ }^{39}$ L.P., doc.61. 
documentadas oito das nove freguesias que no presente integram o referido concelho e, destas, são já mencionados dez lugares ${ }^{40}$.

A toponímia do concelho de Santa Comba fornece igualmente informações preciosas, a saber: a maioria dos nomes de lugar provém de nomes comuns nos quais predominam os de origem vegetal - Campolinho, Gestosa, Pinheirinho, Pinheiro, Vale Pinheiro, Relvas, Silvares, Soito e Vimieiro ${ }^{41}$; inexistência de nomes arábicos e latinos a que se contrapõem o número expressivo de antropónimos de origem germânica - Cagido, Nagosela ${ }^{42}$, Oveiro e Rojão ${ }^{43}$. A hagiotoponímia está presente em cerca de 33\% dos nomes das freguesias. Os santos epónimos, ou oragos daquelas, pertencem quer à Igreja universal - S. João, Santo Estêvão, S. Jorge, Santa Eufémea - quer à do Ocidente - Santa Comba e S. Paio.

As terras de Santa Comba, situadas nos confins da Galécia, na instável fronteira cristã, devem o seu precoce repovoamento a três factores: a protecção divina, a fecundidade do solo $^{44}$ e a força e intrepidez dos homens.

À sombra tutelar de Santa Comba, a virgem mártir cujo culto foi difundido certamente pela Casa real asturo-leonesa, desenvolveu-se um território que buscava no exemplo do testemunho de fé oferecido pelo seu orago a coragem de que necessitava para lutar no dia a dia. Os campos ubérrimos do vale do Dão recompensavam generosamente o esforço dispendido. Mas foram os condes de Coimbra, estreitamente aparentados com a família real, os animadores desta

${ }^{40}$ Cfr. índice toponímico no final deste trabalho.

${ }^{41}$ Cfr. VELOSO, Maria Teresa Nobre - "A flora entre Douro e Mondego segundo a fitotoponímia do Livro Preto da Sé de Coimbra" in Anuário da Sociedade Broteriana, LXVII, 2009, p. 9-40.

${ }^{42}$ Nagosela continua a ser, como há mil anos, uma terra ubérrima em grande parte devido ao curso permanente da água da ribeira que a atravessa. A excepcional fertilidade dos campos valeu-lhe o epíteto de "celeiro do concelho". Esta razão justifica a disputa pela sua tutela administrativa que está documentada, pelo menos, desde o século XIX. A partir de 1984 é uma freguesia do concelho de Santa Comba. Uma velha e ingénua lenda que tenta explicar a origem de tão inusitado topónimo na recusa da venda de ovos à condessa Mumadona Forjaz não tem qualquer fundamento. O dito topónimo é derivado do nome do proprietário da antiga villa de Énego, isto é, a propriedade de Enegozi. O patronímico daquele nome, de origem ibérica, subsiste também actualmente no antropónimo Ingote (Coimbra) aqui documentado em 975 sob a forma Ennegot. Sobre a origem lendária de Nagosela, cfr. FERREIRA, Francisco António Antunes Gonçalves - ob. cit., p. 63.

${ }^{43}$ Cfr. PIEL, J. M. - "Os nomes germânicos na toponímia portuguesa" in Boletim de Filologia, II e seg. Lisboa, 1933-1938.

${ }^{44}$ Deve ter sido esta riqueza agrícola que determinou o facto de alguns prelados de Coimbra se terem intitulado condes de Santa Comba. Cfr. Livro das Vidas dos Bispos, p. 206. 
gesta heróica. O que a força das armas não obtinha - fixar os homens à terra recém-conquistada - conseguiam, por iniciativa daqueles ilustres magnates, as casas monásticas que paulatinamente se iam erguendo como estrelas na Via Láctea. Humílimos ascetérios como S. Jorge (junto ao Cris), Treixedo, Currelos ou Speraindei, localizados em lugares recônditos, iluminavam as trevas que cobriam, com denso manto, a insegurança dos homens naqueles tempos difíceis. Viseu, elevada por momentos a capital dos confins da Galécia, lugar de repouso das cinzas do último rei dos visigodos, imprimia à luta entre cristãos e agarenos daquelas paragens o mesmo estímulo que as venerandas relíquias de S. Tiago incentivavam, não só em Compostela, mas em toda a Hispânia.

\section{Apêndice I - Índice Toponímico*}

Adon $\rightarrow$ Dão

Alon $\rightarrow$ Dão

ALVARIM (Alvarin, Alvarini), 1. da freg. Dardavaz, c. Tondela: 1, 1-A, 2, 2-A, 64, CXXX.

ANTA (Antea, Hanta), 1. da freg. Vimieiro, c. Santa Comba Dão: 64, 630.

Aom, Aon $\rightarrow$ Dão

ASNOS (Asinos, Asinus), r.: parte final do rio Pavia, afluente do Dão: 155, 286, 294.

* O presente índice diz respeito aos topónimos que outrora integravam, lato sensu, as terras de Santa Comba. Aqueles vêm mencionados no L. P. e nos Diplomata et Chartae = (D. C.). Na elaboração do referido índice seguimos o critério usado na edição do citado cartulário da Sé de Coimbra, a saber: actualizam-se os nomes latinos e medievais. As formas modernas apresentam-se compostas em versaletes e, entre parêntisis, as respectivas variantes seguidas do número do documento do L.P., em algarismos árabes; e em romano, o dos D.C. As abreviaturas utilizadas - c., freg., 1., loc., r., significam respectivamente concelho, freguesia, lugar, lugar indeterminado e rio. 
COUTO DE BAIXO (Sancta Eolalia), freg. c. Viseu: LXXX.

CRIS (Crines, Crinis), r.: afluente do Dão: 191.

CURRELOS (Olibaria de), freg. c. Carregal do Sal: CXXX.

DÃO (Adon, Alon, Aom, Aon, Huone), r.: 1, 1-A, 2, 2-A, 64, 80, 151, 271, $301,630$.

DINHA (Inia), r.: afluente do Dão: 51, 51-A.

ESPRENDEO (Speraindeo), hoje Mosteirinho, 1. da freg. Couto de Baixo, c. Viseu: LXXX.

Ferronio, loc.: LXXX.

FONTE DO OURO (Fonte Aurea), 1. da freg. S. João de Areias, c. Santa Comba

Dão: 630 .

GESTOSA (Genestosa), 1. da freg. Couto do Mosteiro, c. Santa Comba Dão:

2, 2-A, 64, CXXX.

LOUROSA (Laurosa), freg. c. Viseu: LXXX.

NAGOSELA (Enegosela), freg. c. Santa Comba Dão: 61, CXXX.

ÓVOA (Ovola), freg. c. Santa Comba Dão: 64.

PAPÍZIOS (Papizinos), freg. c. Carregal do Sal: CXXX.

PINHEIRO DE ÁZERE (Pineiro), freg. c. Santa Comba Dão: 64.

ROJÃO GRANDE (Rageoi, Ragoi), 1. da freg. Vimieiro, c. Santa Comba Dão: 3.

- PEQUENO, 1. da freg. Pinheiro de Ázere, c. Santa Comba Dão: 64.

SABUGOSA (Savugosa), freg. c. Tondela: LXXX.

Sancta Eolalia $\rightarrow$ COUTO DE BAIXO

SANTA COMBA DÃO, c. e freg.: 1, 1-A, 2, 2-A, 3, 64, 68, 78, 80, 422, 663.

SANTA EUFÉMIA, 1. da freg. Óvoa, c. Santa Comba Dão: 660.

SÃO JOANINHO (Sanctum Johanninum), freg., c. Santa Comba Dão: 3.

SÃO JOÃO DE AREIAS (Sancto Johanne de Teliada), freg. c. Santa Comba

Dão: 1, 1-A, 2, 2-A, 3, 64, 630, CXXX.

SÃO JORGE, 1. e most. da freg. S. Joaninho, c. Santa Comba Dão: 1, 1-A, 2 ,

2-A, 3.

SILVARES, 1. da freg. S. João de Areias, c. Santa Comba Dão: CXXX.

TRAVANCA, 1. da freg. Oliveira do Conde, c. Carregal do Sal: CXXX.

Traxedilina $\rightarrow$ VILA NOVA DA RAINHA

TREIXEDINHO (Treisedino), 1. da freg. de Treixedo, c. Santa Comba Dão:

64.

TREIXEDO (Traixedo, Traxede, Traxedis, Traxedo, Treixede, Treixedis, Trexedi,

Trexete, Trexui, Truxedo), freg., c. Santa Comba Dão: 1, 1-A, 2, 2-A, 61, 68.

VILA NOVA DA RAINHA (Traxedilina), freg. c. Tondela: CXXX.

VILA POUCA (Villa Pouca), 1. da freg. S. Joaninho, c. Santa Comba Dão: 3.

VIMIEIRO (Vimineiro), freg. c. Santa Comba Dão: 64. 


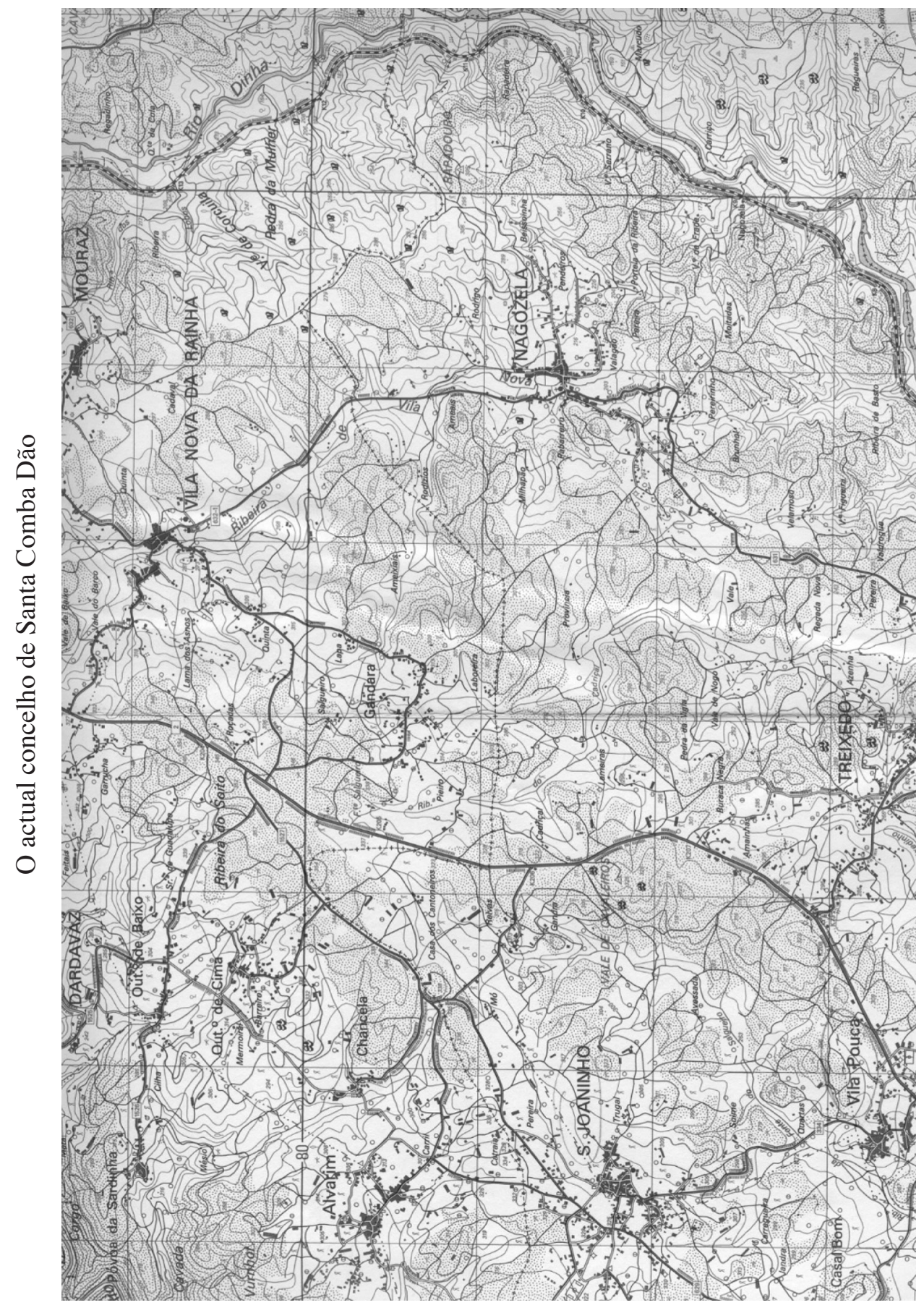




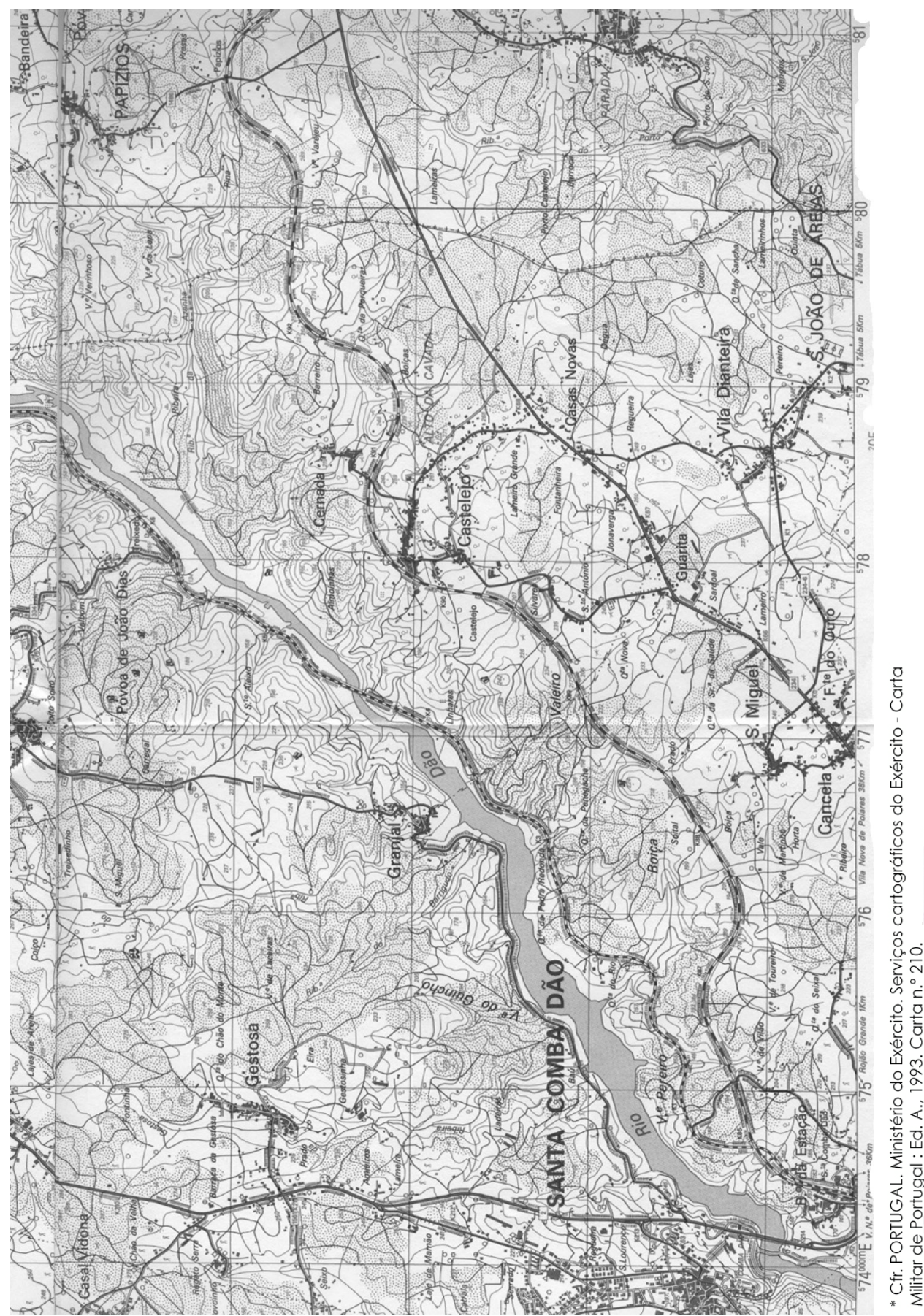




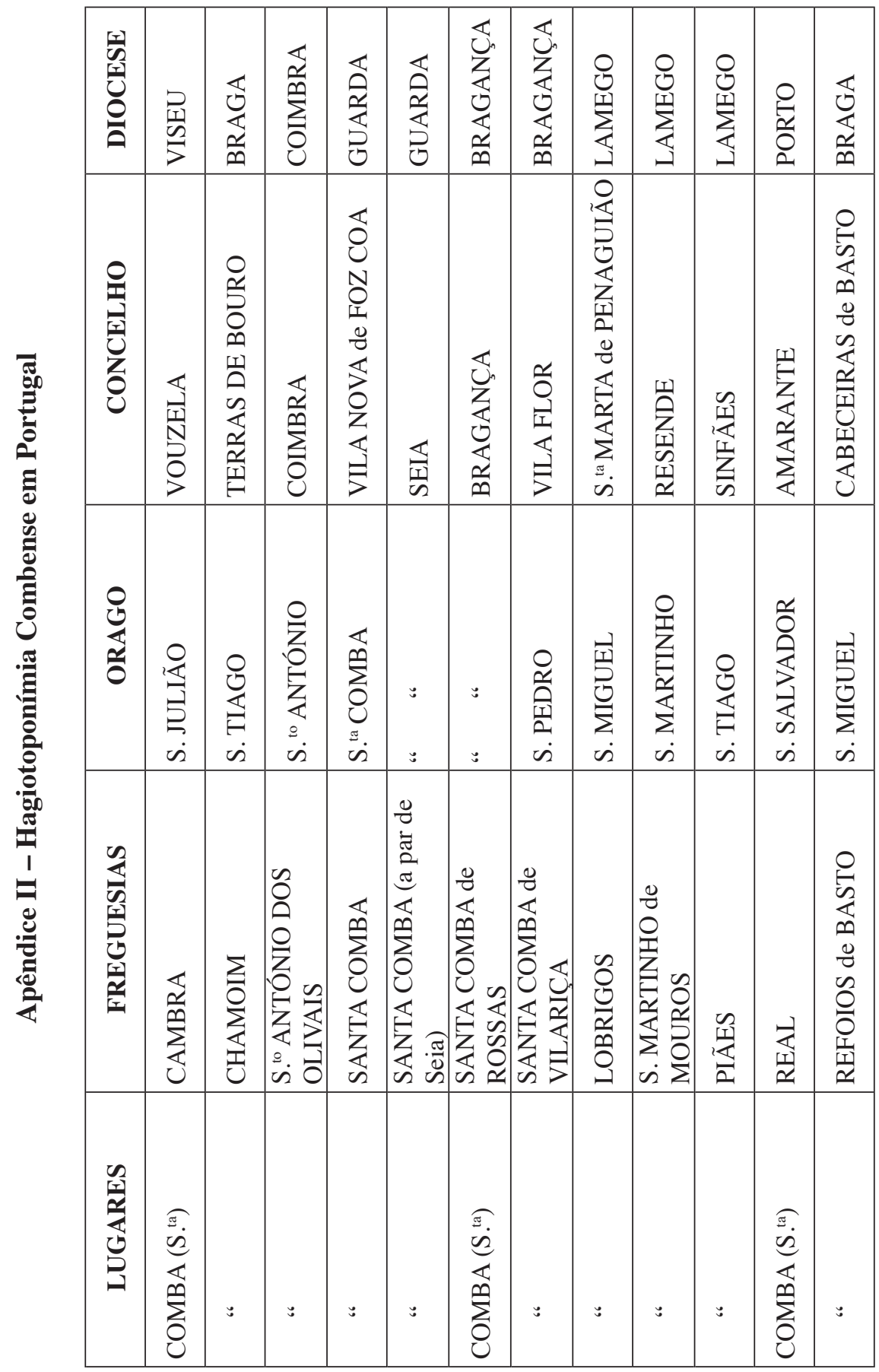




\begin{tabular}{|c|c|c|c|c|c|c|c|c|c|c|c|c|c|}
\hline 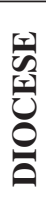 & 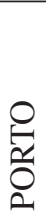 & 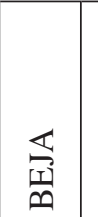 & $\begin{array}{l}0 \\
\stackrel{0}{0} \\
0 \\
0\end{array}$ & $\begin{array}{l}0 \\
\stackrel{0}{\alpha} \\
0 \\
0\end{array}$ & 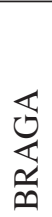 & 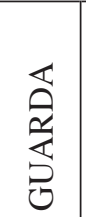 & 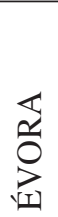 & 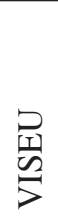 & 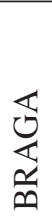 & : & : & 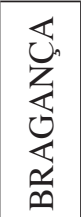 & 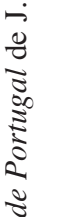 \\
\hline 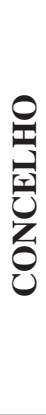 & 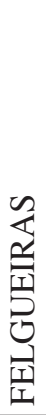 & 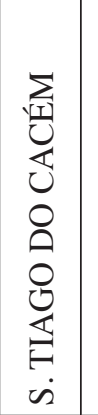 & 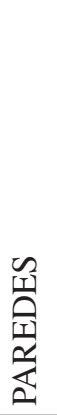 & 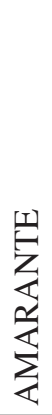 & 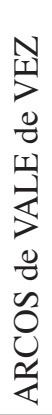 & $\underset{\Omega}{\overleftarrow{\Omega}}$ & $\begin{array}{l}0 \\
2 \\
0 \\
z \\
0 \\
0 \\
0 \\
\sum_{0=1}^{0} \\
\vdots \\
z \\
0 \\
\vdots\end{array}$ & 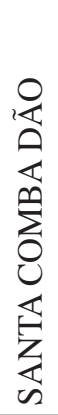 & 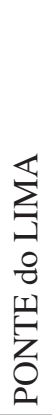 & $\begin{array}{l}: \\
:\end{array}$ & $\begin{array}{l}: \\
: \\
:\end{array}$ & 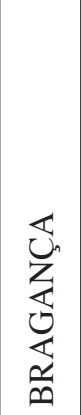 & 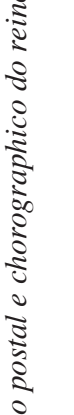 \\
\hline ְ. & $\begin{array}{l}\mathbb{1} \\
\sum_{0}^{\infty} \\
\text { is } \\
\text { is }\end{array}$ & 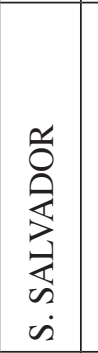 & 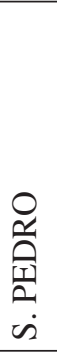 & $\begin{array}{l}\text { 告 } \\
\text { 竞 } \\
\text { 紊 } \\
\text { is } \\
\text { is }\end{array}$ & 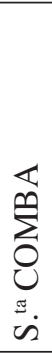 & 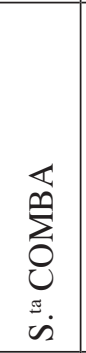 & 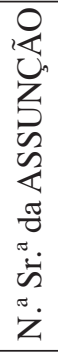 & 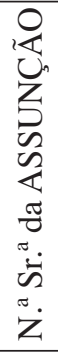 & 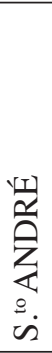 & 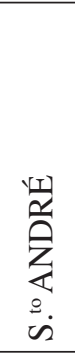 & 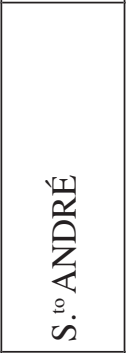 & 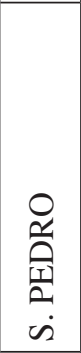 & 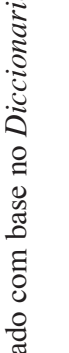 \\
\hline 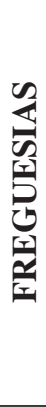 & 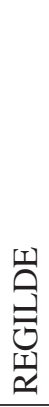 & $\begin{array}{l}\text { 㞤 } \\
\text { 㫕 }\end{array}$ & 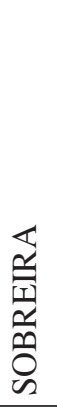 & $\begin{array}{l}\text { 焉 } \\
\text { 至 }\end{array}$ & 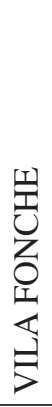 & 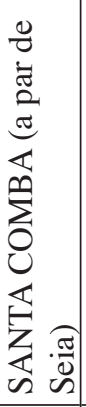 & 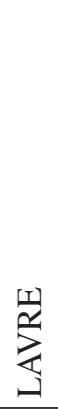 & 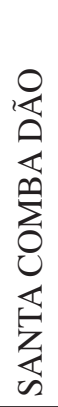 & 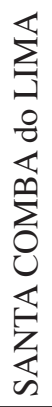 & : & : & 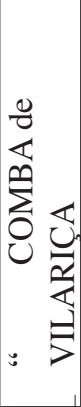 & 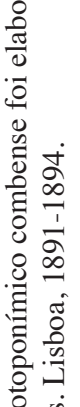 \\
\hline 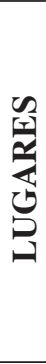 & : & 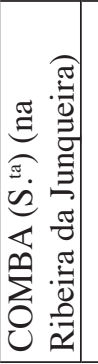 & : & 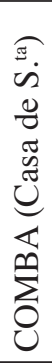 & 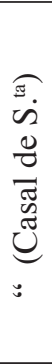 & 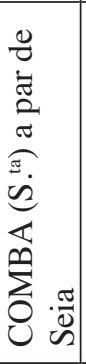 & 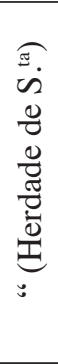 & 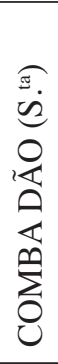 & 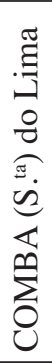 & 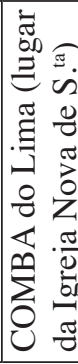 & 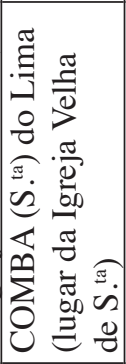 & 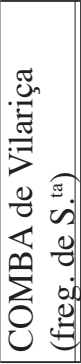 & 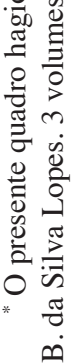 \\
\hline
\end{tabular}


